\title{
SYSTEM INTEGRATED MANAGEMENT FOR STOCK MANAGEMENT IN A BEVERAGE DISTRIBUTOR: A PROPOSAL BASED ON A CASE STUDY
}

\author{
Fernando Custódio Stankevecz ${ }^{1}$, Izamara Cristina Palheta Dias ${ }^{2}$
}

\author{
${ }^{1}$ Student - Centro Universitário Campos de Andrade - Uniandrade. Curitiba - PR - Brasil. \\ ${ }^{2}$ Producer Engineering - Centro Universitário Campos de Andrade - Uniandrade. Curitba - PR - Brasil.
}

Email: fernando.stankevecz@gmail.com, izamarai@hotmail.com

Received: March 26th, 2019

Accepted: April 29th, 2019

Published: June 30 3019

Copyright $(2016$ by authors and Institute of Technology Galileo of Amazon (ITEGAM). This work is licensed under the Creative Commons Attribution International License (CC BY 4.0). https://creativecommons.org/lice nses/by/4.0/

\begin{abstract}
Inventory management in a micro and small enterprises is mostly done through the common sense of the owners. The correct inventory management focuses not only on avoiding the lack of certain products, but also on maintaining them correctly with well-defined policies and demonstrating wellaligned processes. The present study proposes the implementation of an Integrated Management System (GIS) in a Beverage distributor in the metropolitan region of Curitiba, located in the municipality of São José dos Pinhais. With the implementation of GIS, it will be possible to analyze and define such policies, since the company today works with the management of the stock through the empirical knowledge of the managers, the acquired over time. In order to carry out the study, a bibliographic research was conducted on Integrated Management System and on inventory management, in order to base the importance of such management and what its benefits for the company after the implementation. Subsequently, a quantitative analysis of the stock of the company under study was also carried out in order to base what was evidenced in the research and thus justify the importance of such control. Moreover, through the history generated by the GIS, verify what are the impacts of the stock policies applied to companies in the beverage distribution sector. Therefore, being aware of how inventory control affects your market strategies and what are the right policies to adopt because they are small businesses.
\end{abstract}

Keywords: Management, Inventory, Integrated Management Systen, Control.

\section{RESUMO}

A gestão de estoques em micro e pequenas empresas acontece na grande maioria através do senso comum dos proprietários. $\mathrm{O}$ correto gerenciamento dos estoques não foca apenas em evitar a falta de determinados produtos, mas também a sua correta manutenção com políticas bem definidas e que demonstrem processos bem alinhados. O presente estudo propõe a implantação de um Sistema Integrado de Gestão (SIG) em uma distribuidora de Bebidas da região metropolitana de Curitiba, localizada no município de São José dos Pinhais. Com a implantação do SIG será possível a identificação da correta política de estoques a ser seguida pelo grupo de produtos com que trabalham e a análise e definição de tais políticas, pois a empresa hoje trabalha com o gerenciamento do estoque através do conhecimento empírico dos gestores, este adquirido com o tempo. Para realização deste estudo realizou-se uma pesquisa bibliográfica sobre Sistema Integrado de Gestão e sobre gerenciamento de estoque, afim de embasar a importância de tal gerenciamento e quais seus benefícios para a empresa em tese após a implantação. Posteriormente, também, foi realizada análise quantitativa do estoque da empresa em estudo para assim embasar o que foi evidenciado na pesquisa e assim justificar a importância de tal controle. Além do mais, através do histórico gerado pelo SIG, verificar quais são os impactos das políticas de estoque aplicadas as empresas do setor de distribuição de bebidas. Portanto, ter consciência como o controle de estoques afeta suas estratégias de mercado e quais as politicas corretas a se adotar por se tratar de empresas de pequeno porte.

Palavras-Chaves: Gerenciamento, Estoques, Sistema Integrado de Gestão, Controle. 


\section{INTRODUÇÃO}

Para [1] é recente que as empresas perceberam a grande importância do gerenciamento de estoques e segundo [2], as empresas trabalham com estoque de diferentes tipos e que necessitam ser administrados. Atualmente o gerenciamento de estoques vem gerando vantagem competitiva as empresas. Para as empresas sobreviverem na nova era do consumo e instabilidade do mercado, é necessário um gerenciamento adequado do mesmo onde se possa saber exatamente o que se tem no estoque e quando se deve reabastecer. Sendo assim é necessário um gerenciamento adequado de estoque onde se possa controlar exatamente a alimentação dos produtos no estoque.

Segundo [3] nessa nova era de consumo onde o crescimento da economia acontece de forma desenfreada, as empresas encontram dificuldades em integrar informações. Surge então a implantação de Sistemas Integrados de Gestão - SIG - que busca a integração de todas as informações das empresas (Técnicas de qualidade, sustentabilidade social, e proteção a integridade física e a saúde de seus funcionários).

Refletindo sobre este cenário, o presente trabalho propõe a implantação de um sistema de integração para gerenciamento de estoques em uma distribuidora de bebidas, identificando os principais pontos em que é possível encontrar gargalos relacionados ao alto nível de estoque e estabelecer uma classificação de itens. Com a implantação do sistema integrado consegue-se definir uma política de estoques adequada ao fornecedor de acordo com o grupo de produtos distribuídos por ele, baseando-se na demanda e no nível de serviço que a empresa deseja oferecer a cada item do estoque. Utilizando o conceito do sistema integrado de gestão (SIG) que é a soma de todas as informações interdependentes de uma empresa e que seus resultados são muito maiores do que a atuação de cada etapa em separado. Esta soma compreende uma combinação total da estrutura operacional de trabalho ou toda a documentação gerada em procedimentos gerenciais e técnicos.

Com a globalização, o crescimento da economia e a competitividade no mercado, está crescente a procura por SIG's, pois a utilização dos sistemas eleva o nível de serviço e consequentemente atingindo o objetivo final a satisfação do cliente.

Conforme estudo teórico realizado referente a SIG e gerenciamento de estoque foi possível observar os benefícios e vantagens com a implantação e o desenvolvimento dessas ferramentas em uma empresa que não conta com nenhum gerenciamento, podendo assim vir a garantir a satisfação dos clientes e a saúde da empresa em questão, possibilitando a identificação de possíveis gargalos para que sejam tomadas as medidas cabíveis.

O estudo de caso baseia-se na implantação de um SIG para gerenciamento de estoque em uma distribuidora de bebidas de pequeno porte, na cidade de São José dos Pinhais - PR, é uma ferramenta de grande importância para o desenvolvimento e avaliação dos sistemas SIG.

O presente estudo visa mostrar como a implementação de um sistema de gestão integrado dará suporte ao gerenciamento de estoques em uma distribuidora de bebidas. Após as a implantação do mesmo poderemos avaliar os impactos de políticas de estoque para empresas do setor e como estes podem influenciar suas estratégias de mercado, e como tal ferramenta pode trazer benefícios para quem a utiliza.

\section{REFERENCIAL TEÓRICO}

\section{II.1 SISTEMAS INTEGRADOS DE GESTÃO APLICADOS A ESTOQUES}

Para [3] definem SIG como a soma de todas informações interdependentes de uma empresa e que seus resultados são maiores do que a atuação em separado. Já [4] define o SIG como uma combinação do total da estrutura operacional de trabalho de uma empresa ou de toda a fábrica documentada em procedimentos gerenciais e técnicos.

De acordo com [3] o SGI nasce da necessidade de integrar as informações da empresa no geral. Para [4], com a implantação do SIG consegue-se aumentar a capacidade, aumentar a produção com maior qualidade e com um custo muito menos, evitando desperdícios de tempo e esforços.

Segundo [5] relata que foi no início da década de 80 que a exigência do mercado aumentou. Assim, surgiu a necessidade de aliar todas as informações e aspectos como qualidade e custo. Com a junção das informações no SIG permite-se um controle total das informações geradas por uma empresa que resulta em uma maior previsão e assertividade, possibilitando o controle total e permitindo maximizar lucros e diminuir os custos.

Segundo [6], desde que o homem começou a manusear e desenvolver máquinas para produção de bens de consumo, as indústrias passaram a dar mais importância aos sistemas de gestão de estoques, como plano mestre de produção, MRP I (Planejamento das Necessidades de Materiais), MRP II (Planejamento dos Recursos de Manufatura) e o ERP (Planejamento dos Recursos da Empresa).

\section{II.2 GERENCIAMENTO E CONTROLE DE ESTOQUE}

Para [7], o controle é elemento fundamental em qualquer etapa de um sistema produtivo, iniciando no planejamento, passando pela entrada da matéria-prima até a expedição do produto final.

Segundo [6] o desafio do gestor de estoques está em saber quando será necessário o reabastecimento de cada um dos materiais envolvidos e qual a quantidade deve ser mantida no estoque de segurança. Ainda para os autores, a gestão também é elemento fundamental para a redução de estoques, controles dos custos envolvidos e melhoria do nível de serviço prestados pelas empresas.

De acordo com [8] falam que o gerenciamento do estoque tem que estar alinhado com as estratégias da empresa, sendo necessária uma classificação dos itens de acordo com sua importância e características em comum. Ainda [8] falam que tais produtos devem ser ordenados decrescentemente baseando-se em fatores tais como volume de vendas, margem de lucro, valor do estoque, rotação e natureza do item. Assim os produtos com as mesmas características são agrupados e recebem codificação ou descrição especifica.

Para [9] falam que o gerenciamento de estoque é de extrema importância no âmbito financeiro e operacional, pois o mesmo pode definir os rumos de uma empresa.

Segundo [10] usando a informação do plano mestre de produção (PMP) consegue-se projetar o estoque a frente do tempo, já que o mesmo considera itens que foram produzidos e suas quantidades, contendo informações do que foi produzido e das demandas futuras. Para [11], a técnica do MRP I (Planejamento de necessidade de materiais) permite-se determinar a necessidade de compra de materiais que se não utilizados na fabricação de determinado produto, facilitando a visualização do estoque e 
permitindo minimizar os custos para manter, já que é possível ter uma visão do sistema como um todo.

\section{II.2.1 ESTOQUES}

Para [12], estoque se define como todos os recursos que são armazenados por uma dada empresa: matérias-primas, insumos, componentes, produtos em processo e produtos acabados que podem aparecer em vários pontos da cadeia logística da empresa.

$\mathrm{O}$ armazenamento de determinados recursos consiste em aloca-los de maneira correta, para que quando necessários estejam disponíveis no físico e no sistema, garantindo que o recurso esteja disponível para que a distribuição ocorra,

Para manter esses estoques os custos são altos devido a sua manutenção e o capital empregado em grandes quantidades estocadas, isso vem mostrando uma grande oportunidade de economia nos custos operacionais, otimizando-os cada vez mais podemos maximizar os lucros. [13] identificaram a preocupação dos gestores de empresas com recursos financeiros investidos em grandes quantidades de estoque armazenados.

Para [6], o gerenciamento dos materiais envolvidos em dado processo depende do estabelecimento de uma política de estoque adequada, e também o estudo da necessidade desse material em dados momentos através do histórico de demanda, ainda [14], dizem que se faz necessária uma análise criteriosa desses dados para se garantir um controle correto do mesmo.

\section{II.2.2 TIPOS DE ESTOQUES}

Para [10] comenta que as várias razões para desiquilíbrio entre taxa de fornecimento e de demanda em diferentes pontos de qualquer operação leva a diferentes tipos de estoque.

A analogia da caixa-d'água de uma residência por [15] é muito adequada. A figura 1 mostra esquematicamente o estoque.

Através dessa analogia identifica-se que a taxa de fornecimento não pode ser maior que a taxa de saída, quando os itens têm uma velocidade de entrada maior que a de saída, o nível de estoque aumenta.

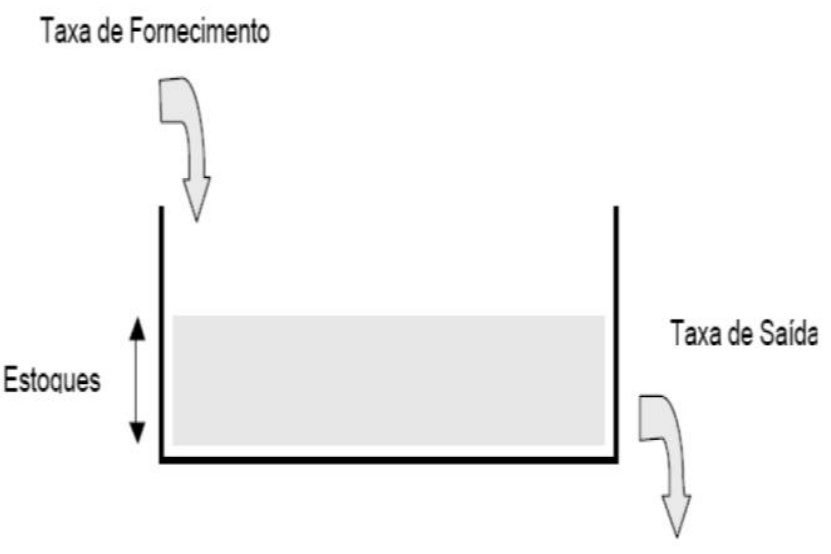

Figura 1 - Analogia dos estoques Fonte:[15].

A seguir os tipos mais comuns de estoque segundo [10] e [16], conforme o quadro 1.
Quadro 1: Tipos de Estoque.

\begin{tabular}{|c|c|}
\hline \multicolumn{2}{|c|}{ TIPOS DE ESTOQUE } \\
\hline Estoque de segurança & $\begin{array}{l}\text { O principal objetivo do estoque } \\
\text { de segurança é compensar } \\
\text { incertezas quanto ao } \\
\text { fornecimento e demanda de } \\
\text { determinado produto. Com } \\
\text { isso, protege-se a empresa } \\
\text { contra excessos de demanda. } \\
\text { O cálculo para se determinar o } \\
\text { tamanho do estoque de } \\
\text { segurança leva em } \\
\text { consideração fatores que } \\
\text { influenciam as incertezas de } \\
\text { mercado, como demanda } \\
\text { variável, o nível de serviço } \\
\text { pretendido, previsões errôneas, } \\
\text { o tempo necessário para o } \\
\text { reabastecimento e o tempo de } \\
\text { entrega. }\end{array}$ \\
\hline $\begin{array}{l}\text { Estoques sazoanis ou de } \\
\text { antecipação }\end{array}$ & $\begin{array}{l}\text { Estoques sazonais ou de } \\
\text { antecipação são necessários } \\
\text { para atender os períodos de } \\
\text { sazonalidade em que tanto a } \\
\text { demanda do produto acabado } \\
\text { como da oferta de matéria- } \\
\text { prima podem sofrer alterações } \\
\text { drásticas, como por exemplo } \\
\text { frutas e verduras. Com o } \\
\text { estoque sazonal consegue-se } \\
\text { compensar a diferença entre o } \\
\text { ritmo de fornecimento e } \\
\text { demanda. }\end{array}$ \\
\hline Estoque de ciclo & $\begin{array}{l}\text { O estoque de ciclo consiste em } \\
\text { armazenar um determinado } \\
\text { item durante um período de } \\
\text { tempo até que se possa produzi } \\
\text { lo novamente, devido ao fato de } \\
\text { não haver a possibilidade de } \\
\text { produção simultânea a } \\
\text { quantidade armazenada deve } \\
\text { suprir até o próximo ciclo de } \\
\text { produção. }\end{array}$ \\
\hline Estoque em trânsito & $\begin{array}{l}\text { Conhecido como o estoque de } \\
\text { tubulação ou movimento, } \\
\text { refere-se a produtos ou } \\
\text { materiais que estão sendo } \\
\text { movimentados de um ponto a } \\
\text { outro do fluxo logístico. Para } \\
\text { haver redução desse tipo de } \\
\text { estoque, as empresas trabalham } \\
\text { em reduzir o tempo de } \\
\text { movimentação. }\end{array}$ \\
\hline
\end{tabular}




\section{TIPOS DE ESTOQUE}

É o estoque formando por um processo autônomo, o que

Estoque de desacoplamento maximiza a utilização do local e eficiência dos funcionários e equipamentos.

É o estoque que aguarda Estoque no canal de transporte. Apesar de existir o distribuição $\quad$ estoque, não é possível realizar a movimentação até o centro de distribuição.

$\mathrm{O}$ estoque Hedge amortece os impactos da flutuação de mercado. Tem a mesma premissa do estoque de segurança, porém o mesmo, pode funcionar de forma compensatória em possíveis prejuízos (Greves, problemas com a legislação, Preços, etc).

Fonte: Autores, adaptado de [15].

\section{II.2.3 CLASSIFICAÇÃO DE ESTOQUES}

Para [16] observa que "existem muitas maneiras de classificar estoques. Uma classificação frequentemente utilizada se relaciona ao fluxo de materiais que entra em uma organização, passa por ela e dela sai". Devido à sua importância contábil os estoques são classificados em 5 grandes tipos de acordo com a classificação dos materiais nele estocados. (Conforme quadro 2).

Quadro 2: Classificação x Descrição.

\begin{tabular}{|c|c|}
\hline CLASSIFICAÇÃO & DESCRIÇÃO \\
\hline Matérias-primas & $\begin{array}{l}\text { São itens comprados que ainda } \\
\text { não entraram em processo de } \\
\text { produção. São todos os } \\
\text { materiais comprados, peças } \\
\text { componentes e subconjuntos. }\end{array}$ \\
\hline Produtos em processo & $\begin{array}{l}\text { Matérias-primas que já estão } \\
\text { em processo de produção, ou } \\
\text { aguardando para entrar em } \\
\text { processo, também conhecidas } \\
\text { como Work in Process (WIP). }\end{array}$ \\
\hline $\begin{array}{l}\text { Produtos acabados } \\
\text { materiais acabados }\end{array}$ & $\begin{array}{l}\text { São aqueles que já passaram } \\
\text { por todas as etapas do } \\
\text { processo e estão prontos para } \\
\text { serem vendidos. }\end{array}$ \\
\hline Estoques de distribuição & $\begin{array}{l}\text { Produtos acabados que estão } \\
\text { armazenados em um CD } \\
\text { (centro de distribuição). }\end{array}$ \\
\hline $\begin{array}{l}\text { Suprimentos de manutenção, } \\
\text { de reparo e de operação }\end{array}$ & $\begin{array}{l}\text { São todos aqueles itens que } \\
\text { são utilizados na produção, } \\
\text { porém não fazem parte do } \\
\text { produto. }\end{array}$ \\
\hline
\end{tabular}

Fonte: Autores, Adaptado de [15].

\section{II.2.4 CLASSIFICAÇÃO ABC}

Para [10], a curva $\mathrm{ABC}$ ou regra 80/20 preconiza que aproximadamente $80 \%$ das vendas de uma operação são responsáveis por somente $20 \%$ de todo um estoque. Normalmente uma pequena quantia desse estoque simboliza uma grande parte do valor total de estoque.

Segundo [13] dizem que uma classificação ABC normalmente apresenta a seguinte configuração onde produtos considerados da classe A correspondem por $65 \%$ do valor da demanda ou consumo anual, e as classes B e C, correspondem respectivamente, por $25 \%$ e $10 \%$ dessa demanda, conforme mostrado na figura 2 .

Para [8] frisam que para algumas empresas se faz necessária utilização de estratégias adicionais para que se venha a ter um bom gerenciamento do estoque, ficando a critério da mesma a análise de quais informações são relevantes para o alinhamento de seus processos.

Segundo [10], através dessa ferramenta pode-se classificar os mais variados itens mantidos em determinado estoque de acordo pela sua movimentação de valor. $O$ que permite que os responsáveis pelos estoques foquem seus esforços na classe com maior valor agregado:

- Classe A - 20\% de itens de alto valor que representam cerca de $80 \%$ do valor total do estoque.

- Classe B - são aqueles de valor médio, usualmente os $30 \%$ dos itens que representam cerca de $10 \%$ do valor total.

- $\quad$ Classe C - itens de baixo valor que, apesar de compreender cerca de $50 \%$ do total de itens estocados, representam cerca de $10 \%$ do valor total.

De acordo [17] ainda destacam a vantagem na utilização do método de classificação $\mathrm{ABC}$ já que os itens são classificados em A, B e C com base em seus custos, quantidades e outros fatores, de modo que itens importantes tem pequenas quantidades e maior valor, os quais devem ser controlados de forma mais rigorosa.

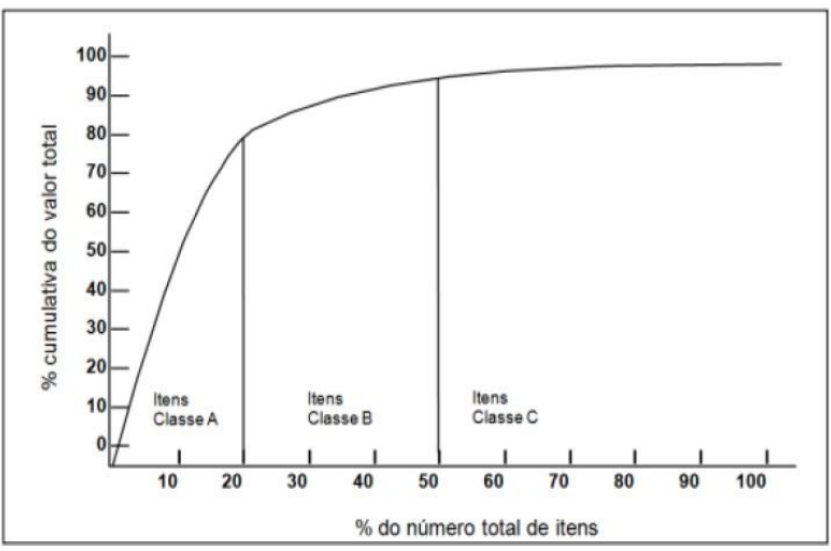

Figura 2 - Curva de Pareto para itens em estoque Fonte: [10].

\section{II.2.5 OBJETIVO DO CONTROLE DE ESTOQUE}

Para [6] o controle de estoque tem por objetivo ter um controle financeiro maior da empresa, já que sua manutenção é cara e com o gerenciamento consegue-se que o capital investido seja minimizado. É através do controle que conseguimos minimizar e mensurar o estoque em trânsito na empresa.

Segundo [12] os estoques possuem uma série de objetivos, tais como: melhorar o nível de serviço, incentivar economias de produção, permitir economias de escalas nas compras e nos transportes, agir como proteção no aumento dos preços, proteger as empresas das incertezas da demanda e do tempo de ressuprimento.

Para o controle eficaz desse estoque se faz necessário um planejamento, um levantamento das informações mais pertinentes 
como data de recebimentos, grau de prioridade, datas de reposição, espaço físico disponível e mais informações pertinentes ao produto trabalhado.

Para [11], "O gerenciamento de estoques, devido ao impacto financeiro do estoque e à sua importância para garantir o abastecimento do cliente, tem técnicas específicas para o seu dimensionamento".

Para tanto é necessário que a empresa conheça perfeitamente o tipo de produto que trabalha e qual a melhor maneira de gerencia-lo, se adequando ao mercado atual. Fazendo com que essa gestão a faça mais competitiva no mercado.

\section{MATERIAIS E MÉTODOS}

O tipo de pesquisa utilizada foi a exploratória. Para [18] pesquisas exploratórias tem como objetivo dar maior familiaridade ao problema em estudo, para torna-lo exposto ou construir possíveis hipóteses relacionadas ao objeto de estudo. Ainda segundo [18], estudos de caso consistem no estudo profundo, que permita um amplo detalhamento do problema.

Como base utilizou-se a pesquisa bibliográfica que é constituída, principalmente, com a pesquisa de livros e artigos científicos relacionados ao assunto de acordo com [18].

\section{RESULTADOS}

\section{IV.1 DESCRIÇÃO DA EMPRESA EM ESTUDO}

O presente estudo foi realizado na Distribuidora de Bebidas Adega Subtil fundada em 2017, localizada em São José dos Pinhais no Bairro Afonso Pena.

A Distribuidora Subtil tem como foco principal a venda no varejo, não realiza entrega e trabalha somente com a chamada venda balcão.

Ela conta com uma câmara fria e estoque seco para armazenagem dos demais produtos. Seu principal foco é o fornecimento de bebidas em geral alcoólicas e não alcoólicas, porém também vende carvão e gelo para complemento. Hoje não conta com nenhum gerenciamento de estoque, a gestão e reabastecimento acontece pelo conhecimento empírico dos proprietários. Por se tratar de uma empresa familiar e sem funcionários externos, a gestão ocorre através do conhecimento dos mesmos, segundo eles, eficaz. (Figura 3).

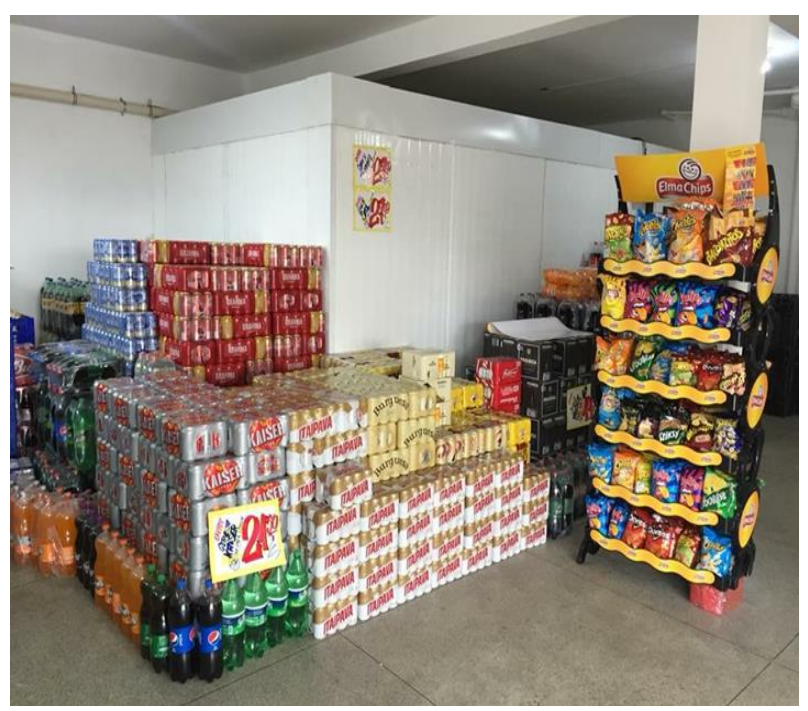

Figura 3 - Distribuidora Adega Subtil.

Fonte: Autores, (2019).

\section{IV.2 FLUXOGRAMA DO PROCESSO}

\section{IV.2.1 FLUXOGRAMA ATUAL}

O processo atual funciona conforme mostrado na figura 4. O pedido de compra é realizado ao fornecedor, após a chegada desse pedido, os produtos ficam armazenados até que ocorra a venda. Após a venda, um novo pedido é feito pelos proprietários se detectada a falta da mercadoria. Conforme mencionado, pelo senso comum do proprietário identifica-se se a quantidade física supre ou não demanda de manda. Devido a este fato não é possível realizar um estudo de previsão de demanda ou de política de estoque adequado.

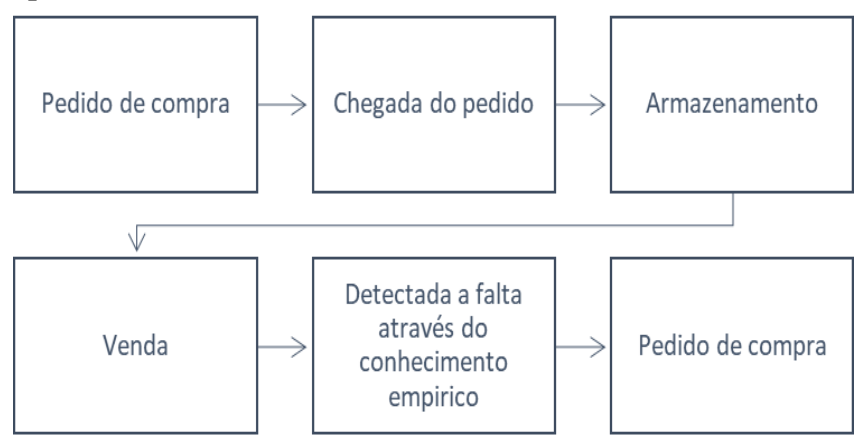

Figura 4 - Fluxograma atual do estoque. Fonte: Autores, (2019).

\section{IV.2.1 FLUXOGRAMA APÓS A IMPLANTAÇÃO DO SIG}

Após a implantação do SIG, o fluxo ocorrerá conforme mostrado na figura 5. Uma vez que o pedido tenha sido realizado e entregue na distribuidora, a NF de entrada deverá ser lançada no sistema para que os produtos possam ser armazenados e postos para a venda. Com o SIG implantando poderá se realizar uma análise e levantamento de quais itens realmente serão necessários, a compra. E assim será gerado um novo pedido. Por fim, será gerado um histórico de venda e compra, podendo se implantar a política de gestão correta e uma previsão de demanda adequada para empresa.

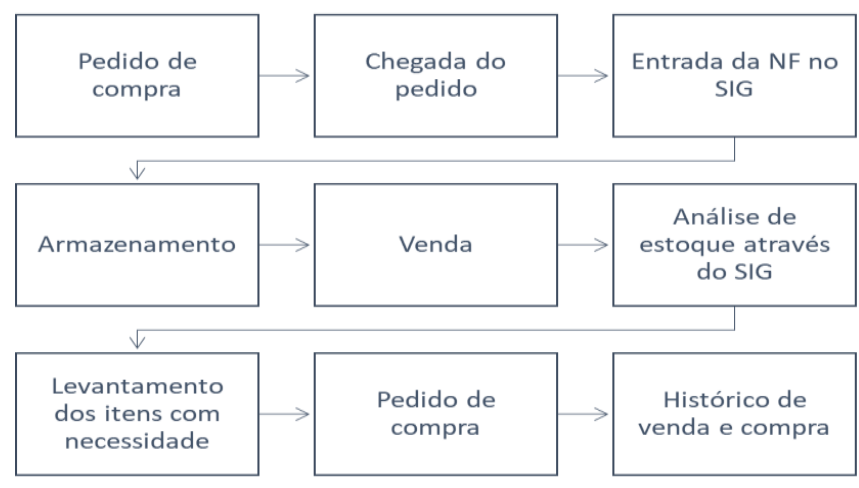

Figura 5 - Fluxograma do estoque após implantação do SIG. Fonte: Autores, (2019).

\section{IV.1 INVENTÁRIO DE ESTOQUE E CURVA ABC}

Foi realizado inventário de estoque para dar inicio ao processo de implantação do sistema integrado de gerenciamento, e mostrar o grau de importância do gerenciamento adequado do estoque, onde os proprietários não tinham idéia da quantidade de produtos e do valor agregado ao seu estoque.

Onde foi utilizada a regra da curva $\mathrm{ABC}$ para classificação de tal, conforme abaixo, onde foi identificado um total de 222 itens 
onde ficaram distribuídos nas seguintes proporções conforme figura 6.

\begin{tabular}{|ccc|}
\hline Classe & Corte & Proporção de Valor \\
\hline A & $80 \%$ & $80 \%$ \\
B & $95 \%$ & $15 \%$ \\
C & $100 \%$ & $5 \%$ \\
\hline
\end{tabular}

Figura 6 - Classificação ABC distribuidora.

Fonte: Autores, (2019).
Onde evidenciamos conforme curva $\mathrm{ABC}$ a distribuição dos itens conforme proporção de valor, conforme regra da curva. Onde a classe A equivale a $80 \%$ do valor de estoque.

Conforme mostrado no gráfico a seguir na figura 7 , vemos que a medida que itens de maior valor apresentam menor volume em estoque, já os itens de menor valor apresentam maiores volumes em estoque.

Com a implantação do gerenciamento dessas quantidades e valores em estoque, se poderá ter uma melhor visão de tal e uma análise correta, já que atualmente não consegue-se saber qual o volume do estoque e o capital investido no mesmo.

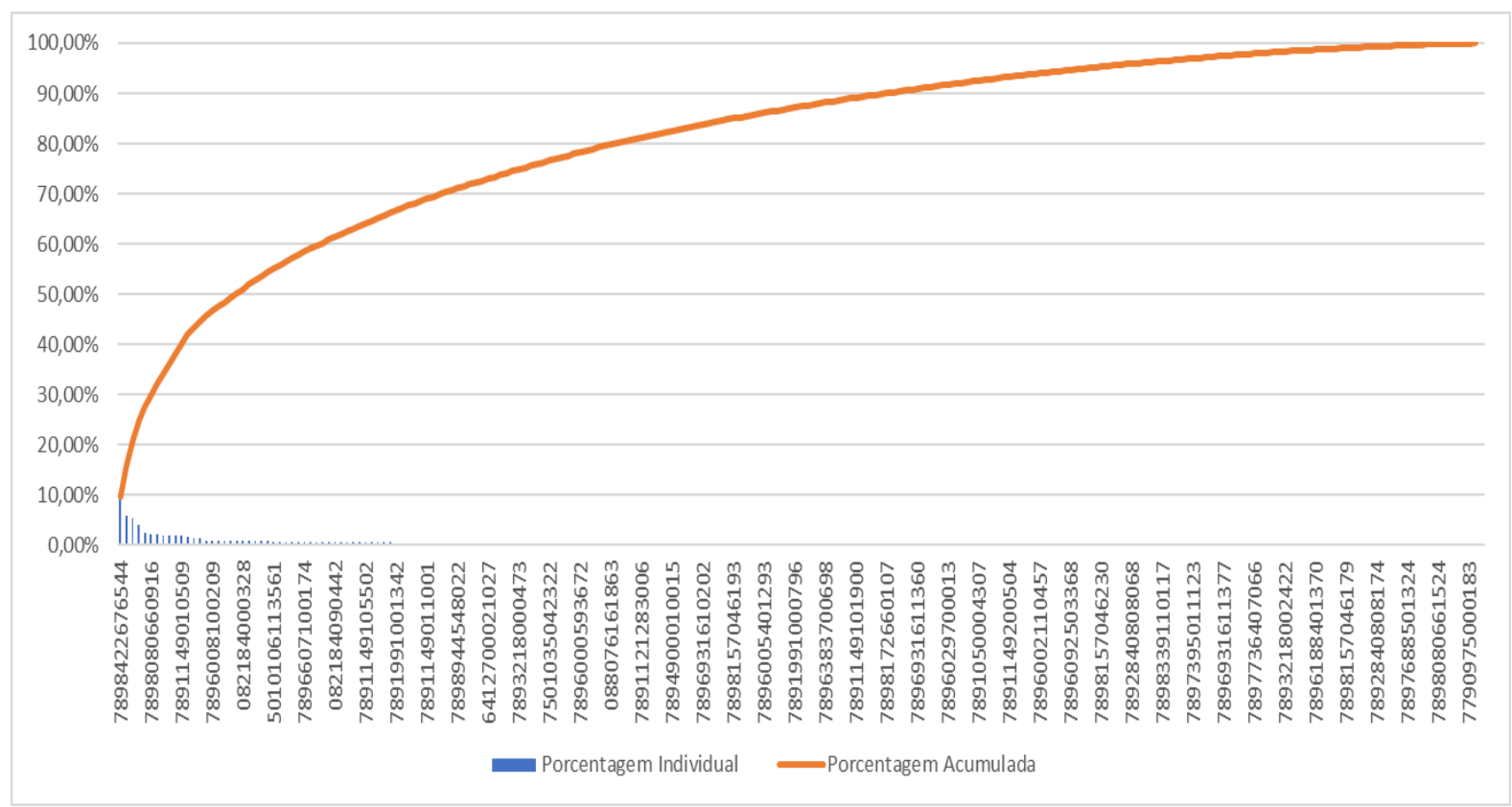

Figura 7 - Curva de Pareto Distribuidora Fonte: Autores, (2019).

\section{CONCLUSÕES}

Após o trabalho de implantação do SIG, poderão analisar e avaliar, através do histórico gerado pelo SIG, quais são os impactos das políticas de estoque aplicadas as empresas do setor de distribuição de bebidas. Como afetam suas estratégias de mercado e quais as políticas corretas a se adotar por se tratar de empresas de pequeno porte.

Com a implantação do SIG a empresa deve gerar um fluxo de processos mais consistente, não se perdem informações. Assim, os gestores do estoque independente do grupo que pertencerem poderão ter uma visão mais ampla do estoque e tomar decisões estratégicas sobre qual produto investir ou não, quando ou não se fazer uma promoção, entre outros fatores que poderão visualizar com a correta gestão do estoque. Assim teremos uma vantagem estratégica mais clara e definida.

Por fim, essa implantação dá aos proprietários uma experiencia de um SIG, e lhes mostra os benefícios da gestão, visto que através deste processo fica claro por fim onde seu capital está investido, sem essa gestão não se é possível ter controle.

\section{REFERÊNCIAS}

[1] Christopher, M. Logística e gerenciamento da cadeia de suprimentos: criando redes que agregam valor. $2^{\circ}$ ed. São Paulo: Cengage Training, 2009.
[2] Tubino, D. F. Planejamento e controle da produção: teoria e prática. São Paulo: Atlas, 2008.

[3] Fernandes, J.; Busanello, F,; Polacinski, E.; Godoy, L.; Losekann,A.; Lorenzett, D.; Etapas necessárias para a implantação de um sistema de gestão integrado. Rev. Adm., UFSM, Santa Maria, v. 8, número 1, p. 60-72, MAR. 2015

[4] Tronco, C. R. et al. Sistema de gestão integrado de qualidade, meio ambiente, saúde e segurança e responsabilidade social - SGI: uma experiência de implantação. In: Simpósio de Engenharia de Produção, XII., 2005, Bauru. Anais...Bauru: I SIMPEP, 2005.

[5] Fonseca, W. R.; Benefícios gerados com a implantação do sistema de gestão da qualidade: um estudo de caso em uma organização no segmento de fundição em Lagoa da Prata MG.TCC de Graduação em Engenharia de Produção. Centro Universitário de Formigas, Formiga, MG, Brasil, 2010.

[6] Marteli, L; Dandaro, F; Planejamento e controle de estoque nas organizações. Revista Gestão Industrial, Universidade Tecnológica Federal do Paraná - UTFPR - Campus Ponta Grossa - Paraná Brasil ISSN 1808-0448 / v. 11, n. 02: p.170-185, 2015

[7] Borges C. T.; Campos S. M.; Borges C. E. Implantação de um sistema para o controle de estoques em uma gráfica/editora de uma universidade. Revista Eletrônica Produção \& Engenharia, v. 3, n. 1, p. 236-247, Jul./Dez. 2010. 
[8] Lima, E; Carmo, B; Pontes, H; Albertin, M. Gerenciamento de estoques em um distribuidor de bebidas. Um estudo de caso. In Encontro Nacional de Engenharia de Produção, 30, 2010, São Carlos, SP, Brasil.

[9] Provin T. D.; Sellitto A. M. V. Política de Compra e Reposição de Estoques em uma Empresa de Pequeno Porte do Ramo Atacadista de Materiais de Construção Civil. Revista Gestão Industrial. v. 07, n. 02: p. 187-200, 2011.

[10] Slack, N. et al. Administração da Produção. 2.ed. São Paulo: Atlas, 2009.

[11] Martins, P. G.; Campos ALT, P. R. C. Administração de Materiais e Recursos Patrimoniais. São Paulo:Saraiva, 2009.

[12] Ballou, R. H. Gerenciamento da cadeia de suprimentos: Planejamento organização e logística empresarial. Tradução Elias Pereira. 5.ed. Porto Alegre: Bookman, 2006.

[13] Corrêa, H. L.; Corrêa, C. A. Administração de Produção e Operações. Manufatura e Serviços: uma abordagem estratégica. 2 ed. São Paulo: Atlas, 2005.

[14] Lopes A. R.; Planejamento e Controle da Produção: Um Estudo de Caso no Setor de Artigos Esportivos de uma Indústria Manufatureira. XXVIII Encontro Nacional de Engenharia de Produção. Rio de Janeiro, 2008.

[15] Bento, A. A Importância da Gestão de Estoques: Estudo de Caso em uma Indústria Automobilística. Florianópolis: 2008.

[16] Arnold, J. R. Tony. Administração de Materiais. Sao Paulo: Atlas, 1999.

[17] Pereira, B.; Chaves, G.; Bellumat, M.; Barboza, M.; Dutra, R.; Gestão de estoque: um estudo de caso em uma empresa de pequeno porte de Jaguaré. In Encontro Nacional de Engenharia de Produção, 35, 2015, Fortaleza, CE, Brasil.

[18] Gil, A. C. Como elaborar projetos de pesquisa. $5^{\text {a }}$ ed. São Paulo: Atlas, 2002. 